\title{
Audience Perception of Newspapers' Editorial Cartoons as Communication Medium
}

\author{
ADETOLA, Samson Adesegun ${ }^{1 *}$, OLUYI, Isaac Adesuyi ${ }^{2}$ \\ ${ }^{I}$ National Agricultural Extension and Research Liaison Services, Ahmadu Bello University, (NAERLS/ABU), \\ Samaru - Zaria, Kaduna State \\ ${ }^{2}$ National Centre for Technology Management, Obafemi Awolowo University, IIe-Ife, Osun State, Nigeria \\ *Corresponding Author: ADETOLA, Samson Adesegun, National Agricultural Extension and Research \\ Liaison Services, Ahmadu Bello University, (NAERLS/ABU), Samaru - Zaria, Kaduna State
}

\begin{abstract}
Editorial, also known as political cartoons are hand-drawn pictures that occupy a single or multiple pictorial frames, frequently complemented by voice bubbles and subtitles referred to as utterances, with written text and serving as an indicator of discussion that the readers are supposed to interpret with the purpose of communicating a message to either a single person, authority or the public. Considered within the theoretical relevance influenced by the assumptions of the Hermeneutic Theory and Symbolic Interactionism Theory, the paper examined the audience perception of newspapers' editorial cartoons as medium of dissemination of information and social agenda setting. It adopted the hermeneutic analysis and survey research methods; while questionnaire served as the research instrument with twenty seven (27) items on it and two selected Nigerian national newspapers - The Punch and The Guardian newspapers - published between January 2017 and December, 2017 were considered on the basis of geographical spread and availability. The analysis carried out revealed that cartoons are used to achieve communicative tasks in Nigerian print media and are creatively used to set agenda thereby providing political commentary and debate in humorous and crafty fashion through which social realities are reflected in the nation's wider socio-political arena. The paper proposes that print media management and cartoonists should not only see cartoons as an entertaining medium, but should also concentrate on how graphic images and messages can be readily understood with suitable drawings, texts and captions, thus serving as a platform for the dissemination of messages.
\end{abstract}

Keywords: audience perception, communication, editorial cartoons, medium, newspapers

\section{INTRODUCTION}

\subsection{Background to the Study}

Visual communicators concentrate on a wide range of distinct techniques to get their point across: photography, digital design, distinctive illustrations, presentations, and even animations, all fall under their wide training and expertise umbrella. While there is more training for visual communicators, graphic designers are not. Their focus is on designing and creating key graphics for insertion of digital and print media, websites, mobile apps, and more. Their focus is restricted to designing and developing main graphics for digital and print media insertion, websites, mobile apps, and more. These two kinds of experts together, however, make it simpler to communicate the main points and marketing attempts of a company in a manner that is bright, vivid and graphically attractive, regardless of the type of media being used (Fahmy, Bock and Wanta, 2014).

Visual images can induce powerful feelings and distinct interpretations as they are used to outsource verbal activities and add to the potential social implications of these pictures being disseminated publicly. They may also have a projective role in the sense that they can generate connections between various issues (Naghy, 2010). Not only in cartoons, but also in social life, humour is a very significant characteristic. Humour is used to differing degrees in cartoons; some cartoons give the audience a smile without being funny, while others are so ridiculous that individuals laugh at them. There are no humour laws, but there are aspects that most individuals may agree with (Mwetulundila and Kangira, 2015). The production of images that are pictures and other illustrative materials is concerned with all visual arts. When these pictures are used in book publishing to convey specific 
information, the art form is usually referred to as illustration. Illustrations talk volumes and are just as essential as printed phrases in a book as a vehicle for communication (Ihebuzor, 2017).

Cartoons plan to interact with each other. They are a mixture of pictures, captions and social comments. Cartoonists encode editorial cartoon voice bubbles and subtitles now referred to as utterances, with texts that the readers are supposed to decode to reach the expected significance. They are written with the purpose of transmitting a message to either a single person, authority or the public. While some readers only appreciate a moment's fun, those who roar with laughter recognize the correct context may shrink anguished by the moral story of the cartoon (Jimoh, 2010).

To represent items within a panel, cartoonist utilizes symbols. These panels are just one moment in time. Unlike in a comic strip, all messages are discovered in an editorial cartoon within the single image, making it complex and hard at first glance to decipher. Some editorial cartoons divide the single panel into distinct sections, maybe quarters, and the items are drawn in a manner which suggests motion development as each section is viewed separately by the viewer. These cartoons are integrated into the editorial cartoon definition as they still exist only as a single visual frame. They are not motion pictures in brief (Kinyua, 2014).

Cartoons can be divided into two classifications: paper and animated ones, if classified by their particular responsibilities. The paper-print cartoons include printed cartoons such as those found in newspapers, magazines or books of comics. Paper-print cartoons are always placed in frames like squares or rectangles. Words or numbers are written mostly within frames or bubbles of thought, but sometimes words outside bubbles of thought are adapted as well (Agba, 2014). On the other hand, animated cartoons can be referred to as comics - a wide term that can be applied to many distinct types of works, ranging from mass-produced superhero comics, classic structured newspaper comics, boundless internet comics, Japanese manga books, Franco-Belgian comic albums, limited edition artworks, journalistic non-fiction comics, educational flyers, to book-length graphics. There are more than one panel of comic strip cartoons. Usually they are a sequence of humorous sketches assembled to create a funny plot. Usually the last panel has the punch line (Agundu, 2017).

Historically, cartoons have been known to address topical problems intrinsic in a particular culture that generally range from wealthy to poor relationships, social iniquities, and even the overall political scenario. Cartoons are significant instruments that can be used in a democracy to reveal policy contradictions and shortcomings. Cartoon tells more than a thousand-word sermon. It can ridicule in a light-hearted way absurdities or other human frailties. So, pomposity, cruelty, hypocrisy, virtues, vanity, and venality are generally the media's main goals of cartoons. Cartoons have played a major role in favourable and negative developments around the globe, as seen in events in Denmark (2005), South Africa (2008) and Rwanda (1993), where cartoons were held accountable, among other media forms, for fueling the 1994 genocide (Mapuwei, 2014).

Editorial cartoons are hand-drawn images that occupy a single or multiple visual frames, often accompanied by written text serving as an indicator of dialog or narration. A notable exception to this definition is the animated editorial cartoon. These animated editorial cartoons are graphically composed on computers and consist of multiple visual frames that follow one another, creating animation (Matthews, 2011). In the news agenda, editorial cartoons operate as a type of visual news discourse and hold a distinctive commentary stance. Cartoon illustrators use creative and rhetorical devices to provide additional (and sometimes alternative) viewpoints on present news occurrences; their visuals become frames for organizing social knowledge as well as capturing the essence of problems or activities. Thus, audiences are provided with a number of different condensing symbols that suggest the core frame of any issue portrayed (Guy, 2016).

Media audiences are the receivers of communication messages. The term audience is very familiar as a collective term for receivers in the simple sequential model of mass communication (Okoro and Onakpa, 2016). Mass media audiences are large, anonymous, scattered, heterogeneous, and active. The mass media audiences are large because they are many, they cannot be easily counted. They are anonymous because they (the audience) are not known to the communicator. The audience members are scattered across different areas and they are made up of different demographics like religion, educational level, and sex, among others (Asemah, 2011). The media audiences stand a better chance to assess newspapers' editorial cartoons because they are consumers of media messages.

Nonetheless, as affirmed by Adetola and Abioye (2020) that pictures are designed to interact and deemed more powerful than words, this study concentrates on the newspaper readers' perception via 
graphic pictures, text and speech, and appraises the communicative responsibilities that editorial cartoons play as communication medium used to set agenda in the nation's wider socio-political arena focusing on two selected widely distributed and long standing Nigerian national print media - The Punch and The Guardian.

\subsection{Objectives of the Study}

1) To determine the proficiency of editorial cartoon as a communication medium by The Punch and The Guardian.

2) To investigate the perception of the newspaper readers towards the use of editorial cartoons by The Punch and The Guardian.

\subsection{Research Questions}

1) How efficient is the proficiency of editorial cartoon as a communication medium by The Punch and The Guardian?

2) To what extent do the readers perceive the message of the newspaper editorial cartoons by The Punch and The Guardian?

\subsection{Scope of the Study}

A collection of quantitative analyzes within the periods of January 2017 to December, 2017 will highlight the ability of the editorial cartoons to provide independent views on changing news events, thus setting the social agenda through the significance of pictures or visual illustrations to illustrate problems and occurrences as published in Nigeria's two chosen leading national newspapers - The Punch and The Guardian. One notable thing about this period is that the year 2017 was the mid-term of the Muhammad Buhari administration while these newspapers were selected based on the criteria of frequency, geographical spread, circulation figures and in addition with regular feature of cartoon pages, as they publish more editorial cartoons than those that have not been selected based on their year of establishment.

\subsection{Theoretical Frameworks}

Few among many theories considered relevant to this paper include Hermeneutic Theory and Symbolic Interactionism Theory.

\subsubsection{Hermeneutic Theory}

Hermeneutic theory is the study of understanding, especially through the systematic interpretation of actions or texts. Hermeneutics originally began as the study or interpretation of the Bible and other sacred works. As it evolved over the last two centuries, it maintained its commitment to the examination of "objectifications of the mind" (Burrell and Morgan, 1979), or what Miller calls "social creations" (Miller, 2005). Just as the Bible was the "objectification" of early Christian culture, and those who wanted to understand that culture would study that text, most modern applications of hermeneutics are likewise focused on understanding the culture of the users of a specific text.

Many communication theorists do not want to explain, predict, and control social behaviour. Their goal is to understand how and why that behaviour occurs in the social world. There are different forms of hermeneutic theory. For example, social hermeneutics has as its goal the understanding of how those in an observed social situation interpret their own lot in that situation. As ethnographer Michael Moerman (1992) explained, social hermeneutic theory tries to understand how events "in the alien world make sense to the aliens, how their way of life coheres and has meaning and value for the people who live it".

Another branch of hermeneutics looks for hidden or deep meaning in people's interpretation of different symbol systems - for example, in media texts. As you might have guessed from these descriptions, hermeneutic theory is sometimes referred to as interpretive theory. Another important idea embedded in these descriptions is that any text, any product of social interaction can be a source of understanding (Baran and Davis, 2010).

The ontology of hermeneutic theory says that there is no truly "real," measurable social reality. Instead, "people construct an image of reality based on their own preferences and prejudices and their interactions with others, and this is as true of scientists as it is of everyone else in the social world" 
(Schutt, 2009). As such, hermeneutic theory's epistemology, how knowledge is advanced, relies on the subjective interaction between the observer (the researcher or theorist) and his or her community.

Put another way, knowledge is local; that is, it is specific to the interaction of the knower and the known. Naturally, then, the axiology of hermeneutic theory embraces, rather than limits, the influence of researcher and theorist values. Personal and professional values, according to Katherine Miller, are a "lens through which social phenomena are observed" (Miller, 2005).

\subsubsection{The Symbolic Interactionism Theory}

Symbolic interactionism is a sociological theory that develops from practical considerations and alludes to people's utilization of dialect to make images. Symbolic interactionism is a micro-level theory that focuses on the relationships among individuals within a society. Communication - the exchange of meaning through language and symbols - is believed to be the way in which people make sense of their social worlds. Theorists Herman and Reynolds (1994) note that this perspective sees people as being active in shaping the social world rather than simply being acted upon.

George Herbert Mead (1863-1931) is considered a founder of symbolic interactionism though he never published his work on it (LaRossa and Reitzes, 1993). Mead's student, Herbert Blumer, coined the term "symbolic interactionism" and outlined these basic premises: humans interact with things based on meanings ascribed to those things; the ascribed meaning of things comes from our interactions with others and society; the meanings of things are interpreted by a person when dealing with things in specific circumstances (Baran and Davis, 2010). If you love books, for example, a symbolic interactionist might propose that you learned that books are good or important in the interactions you had with family, friends, school, or church; maybe your family had a special reading time each week, getting your library card was treated as a special event, or bedtime stories were associated with warmth and comfort.

\section{LITERATURE REVIEW}

Newspaper is a printed unbound paper that contains news about current political, economic, sociocultural, educational, environmental, scientific-cum-technological and sundry affairs as well as other relevant sales information. However, the evolution of electronic communication and migration of newspapers onto websites and blogs has rendered this term obsolete. Although the political cartoon belongs to the editorial pages of the traditional newspaper, nowadays the vast majority of political cartoons can be found on the internet. Newspaper refers to a daily or weekly publication used to disseminate news to a mass audience. This is why it is defined as an unbound printed publication issued at regular intervals which presents information in words, often supplemented with pictures (Adetola and Abioye, 2020).

However, the implication is that a typical newspaper is characterizes as follows:

- Unlike most bounded publications, newspapers are hardly bounded.

- Like all other print media modes, the content of newspapers is usually permanent to the extent that you can enjoy repeated exposure as long as you can preserve a specific edition of a newspaper.

- It includes a wide range of political, financial, social, environmental, scientific, technological and multidisciplinary interests.

- Periodically available that could be daily, weekly or bi-weekly.

- It is widely covered (Adetola, 2019).

The function of the media is to help individuals uncover the truth by teaching them on public problems and presenting all kinds of proof as background to expose wrongdoing in society, hoping to make it a better place to reside in. The press adopts the use of cartoons as one approach to encode and convey meanings to promote this function. In relation to other communicative types, the Nigerian press seems to favour the use of cartoons as its approach to disseminate information about politics. That almost every Nigerian newspaper and magazine has allocated space for cartoons is a testimony to how significant they are perceived. Because political cartoons are images that challenge the intellect, they are thought to have the authority to enhance and explain meaning. (Agba, 2014).

The cartoonist uses various icons which are symbols representing objects within a bordered object called a panel, or frame. These panels represent a single moment in time: a slice of life caught in mid- 
pose, much like a photograph. Unlike comic strips or comic books (mediums that have multiple panels), all information is found within the single image, thus they may be complicated and difficult to decipher at first glance. Cartoons also utilize specific visual elements in order to replicate human communication. Sound (dialogue, self-talk, music, etc.) is created using words and symbols. Cartoonists lampoon politicians on burning issues in newspapers or magazines. Such cartoons always come out in editorial pages, thus their name, editorial cartoons (Adetola and Abioye, 2020).

Cartoons can either be black and white or coloured, but the editorial cartoons considered in our study are both while the main thrust of this study is the editorial cartoons. It is important to distinguish why this paper embraces the term 'editorial cartoon' instead of other derivatives such as 'newspaper cartoon' or 'political cartoon. In preferring the term 'editorial', Adetola and Abioye (2020) asserted how the medium of publication is not the cartoon's defining adjective. Rather, its expression of argument or opinion becomes its primary descriptor.

The acceptability of an editorial cartoon relies on the purpose behind it, its background and the behaviour of those on the receiving end (Pitcher, 2016). For the most part, political cartoons aim to "preach to the converted" but their derogatory and visual nature often fuels audiences to believe that the cartoonist has overstepped the mark, generating more discussion about an issue than would otherwise have been possible with a written editorial (Adetola, 2019).

The capacity to read an editorial cartoon, along with chart and graph reading, is regarded a fundamental skill. Importantly, if the reader is to grasp their full meaning, they must be read in conjunction with the news of the day, and generally consist of a one-panel illustration aimed at visually depicting and commenting on a specific social event or issue in the news. The news of the day is distorted by political cartoonists to convey what they see as the reality about someone or something. As a result, editorial cartoons are often regarded counter-discourses aimed at undermining and challenging dominant ideologies permeated by traditional news reports by leaders. In doing so, cartoonists are anticipated to be aggressive, often requiring widening of the boundaries of excellence and often leading readers to doubt the validity of the pictures depicted (Pitcher, 2016).

The final element that needs to be present in order for political cartoons to flourish is the audience. The cartoonist needs readers that are savoir-faire and politically mindful. Without an audience that understands the conventions of political cartoons, such as satire and caricature, the messages that are contained therein can be lost, and the message is often not interpreted in the correct manner. In addition, audiences also need to have a clear understanding of political and social issues. Each of these factors plays an important role in determining how a reader decodes the messages contained within a particular cartoon. Irrespective of the status of the audience, these cartoons provide comic relief like any other comic strip, except they raise an issue that is relevant, and run a commentary on the lives of the millions of readers, hence, the synergy and the attributes these cartoons possess just like the editorial (Adetola and Abioye, 2020).

Each of these variables plays a significant role in determining how a reader decodes a specific cartoon's messages. Media audience are the receivers of communication messages. The term audience (or readers as in the context of this study) is very familiar as a collective term for receivers in the simple sequential model of mass communication (Okoro and Onakpa, 2016). Mass media audience are large, anonymous, scattered, heterogeneous, and active. The mass media audience are large because they are many, they cannot be easily counted. They are anonymous because they (the audience) are not known to the communicator. The audience members are scattered across different areas and they are made up of different demographics like religion, educational level, and sex, among others (Asemah, 2011).

Regardless of the audience's status, these editorial cartoons provide comic relief like any other comic strip, except that they raise a specific issue and comment on the life of millions of readers, hence the synergy and qualities that these cartoons possess just like the editorial (Adetola, 2019) while the media audiences stand a better chance to assess newspapers' editorial cartoons because they are consumers of media messages. 


\section{MethodologY}

\subsection{Research Design}

Since this paper focuses newspaper readers' perception in Nigeria, descriptive survey design was selected as the suitable research design. Typically, descriptive research includes the measurement of a variable or set of factors as they naturally occur. The descriptive approach is not about the relationships between variables, but about the description of individual variables (Gravetter and Forzano, 2009).

The study is Hermeneutic analysis, also known as textual analysis. Hermeneutic analysis is a special type of content analysis where subjective meanings are given to a text because the interpreter of the text takes into consideration socio-historic context of the text. Hermeneutic analysis provides a framework that explores all the communicative ability of written texts.

Content and textual analysis were considered suitable for this study, because they are applied to examine any piece of writing or occurrence of recorded communication materials in a systematic way to determine the characteristics of a written material and examining it for patterns, frequency and bias.

\subsection{Population}

Readers (audience) of newspapers in Ibadan, Oyo State formed the target population capable of providing the necessary information for the evaluation of editorial cartoons as a medium of communication. The audience includes entrepreneurs, professionals in private sector, retirees and the unemployed in Ibadan, one of the populated cities in Nigeria. Thus, we can say that we have practically fair representation and also, most of the people are presumed to be literate (and not necessarily educated) and are assume to understand newspapers' stories and illustrations like pictures and cartoons.

\subsection{Sample}

The database contained editorial cartoons collected from The Punch and The Guardian within the stated period. These selected national newspapers' editorial cartoons which focus on stories that range from science and environment; sports; business; lifestyle and entertainment; world news; domestic politics; social themes; foreign affairs among many others were used for analyses.

On the other hand, Ibadan metropolitan city and the Ibadan less city, divided into three

- Owode, First Gate (Iddo Local Government)

- Dugbe (Ibadan, North West Local Government)

- Challenge (Ibadan, South West Local Government)

were used to sort 150 respondents which made up of both probability and non-probability sampling. The three (3) clusters has fifty (50) each. Out of the 150 respondents were, 120 working class - civil servants, organizations and entrepreneurs, while remaining 30 respondents targeted the students, retirees, and the unemployed.

Meanwhile, purposive sampling approach was adopted for the newspapers' content analyses available.

\subsection{Description of Instrument}

The instruments used for this study was questionnaire while textual analysis was used to analyze the content of the editorial cartoons. The information from the audience contained both structured and rating scale questions to elicit their perceptions on editorial cartoons by Nigerian newspapers. This is because of the unlikely privilege of the readers to have time to respond to open-ended questions. The questionnaire was administered personally to respondents.

\subsection{Validity and Reliability of Instrument}

Because this study uses the qualitative approach, validity was ensured in the interpretation of results as the questionnaire instrument (APECQ) was validated by three communication specialists with Mass Communication background. Furthermore, a pilot study was conducted with Guttmann scale of coefficient of reproducibility measuring reliability of consistent of the instrument was used as shown below: 
1 - total error/ total responses

$1-3 / 15$

$3 / 20=0.2$

$1-0.2=0.8$

The calculation yielded $\mathbf{0 . 8}(\mathbf{8 0 \%})$ which was considered very high. Mean and standard deviation were used to answer the research questions while the criterion for accepting or rejecting an item was 2.5. However, to assess internal constructs consistency, the overall credibility of this questionnaire among each constructs was higher than 0.7 , indicating that the constructs has high credibility as shown in Table 1 below:

Table1. Cronbach's Alpha based standard test of reliability and validity in support of the results

\begin{tabular}{|l|l|l|l|}
\hline S/N & Survey items & Number of items & Chronbach's \\
\hline$(1)$ & Efficiency of editorial carton & 7 & 0.74 \\
\hline$(2)$ & Readers perception of editorial cartoon & 4 & 0.83 \\
\hline
\end{tabular}

\section{Results}

Out of the 150 copies administered, 120 respondents were working class - the civil servants, professionals in private sector and entrepreneurs while the remaining 30 respondents aimed the students, retirees, and the unemployed. Implying that 50 respondents were assigned to each of the three (3) clusters which represented the three local governments covered. 40 copies of the questionnaire to the civil servants, professionals in private sector and entrepreneurs and 10 for the students, retirees, and the unemployed in each cluster.

134 copies out of the 150 copies distributed were returned. 14 working class was not returned making actual total $106(88.3 \%)$. 28 copies were returned out of the 30 questionnaires for the students, retirees, and the unemployed, making the return rate $93.3 \%$.

\section{Data Analysis}

Information presentation made from the questionnaires was simple descriptive and inferential method of information analysis. The information were gathered and presented on tables and each variable calculated using percentage scores, contingency cross tabulation using statistical package for social sciences (SPSS).

\subsection{Data Presentation}

Table2. Respondents' Sex Distribution

\begin{tabular}{|l|l|l|}
\hline & Frequency & Percentages (\%) \\
\hline Male & 75 & 56 \\
\hline Female & 59 & 44 \\
\hline & $\mathbf{1 3 4}$ & $\mathbf{1 0 0}$ \\
\hline
\end{tabular}

Source: Field Survey, 2020

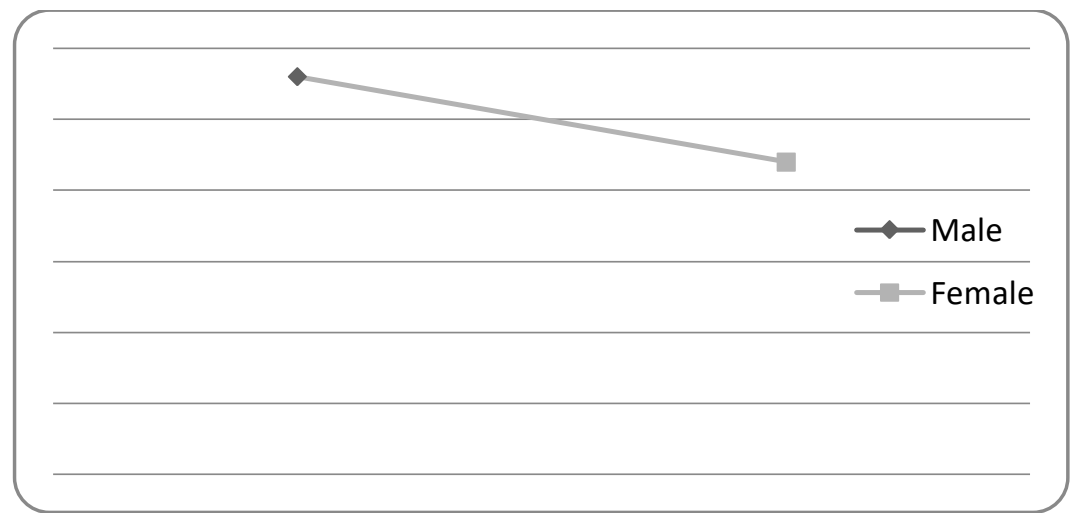

Figure1. Respondents' Sex Distribution

The sex distribution shows $56 \%$ males and $44 \%$ females. However, results information showed the likelihood of males having time for reading newspapers than females. 
Table3. Respondents' Age Distribution

\begin{tabular}{|l|l|l|l|l|}
\hline & Male & Female & Total & $(\mathbf{\%})$ \\
\hline $21-25$ & $6(8 \%)$ & $14(23.7 \%)$ & 20 & 14.9 \\
\hline $26-30$ & $7(9.3 \%)$ & $10(17 \%)$ & 17 & 12.7 \\
\hline $31-35$ & $14(18.7 \%)$ & $13(22 \%)$ & 27 & 20.2 \\
\hline $36-40$ & $14(18.7 \%)$ & $10(17 \%)$ & 24 & 17.9 \\
\hline 41 and above & $34(45.3 \%)$ & $12(20.3 \%)$ & 46 & 34.3 \\
\hline & $\mathbf{7 5 ( 5 6 \% )}$ & $\mathbf{5 9 ( 4 4 \% )}$ & $\mathbf{1 3 4}$ & $\mathbf{1 0 0}$ \\
\hline
\end{tabular}

Source: Field Survey, 2020

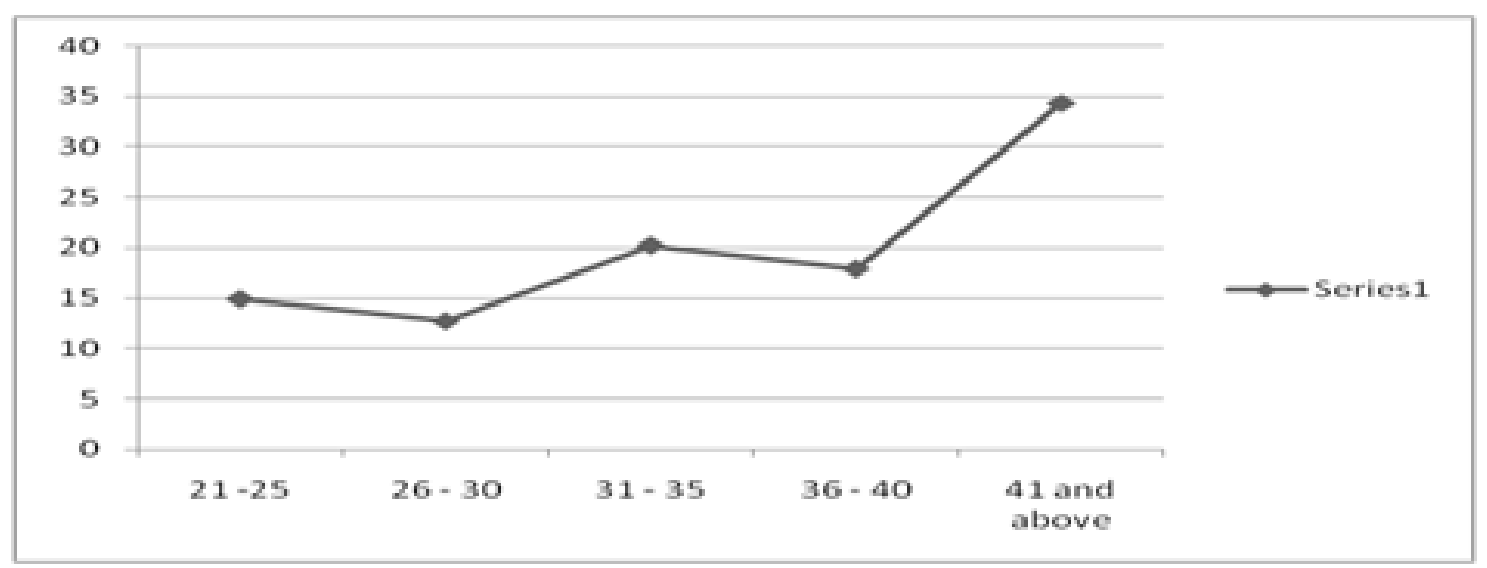

Figure2. Respondents' Age Distribution

Respondents within 21 - 25 were 20 (14.9\%) while respondents within ages of 26 - 30 are $17(12.7 \%)$. Also, the respondents 31 - 35 were 27 (20.2\%), hose within 36 - 40 were 24 (17.9\%). However, the respondents within the age range of 41 and above were $46(34.3 \%)$.

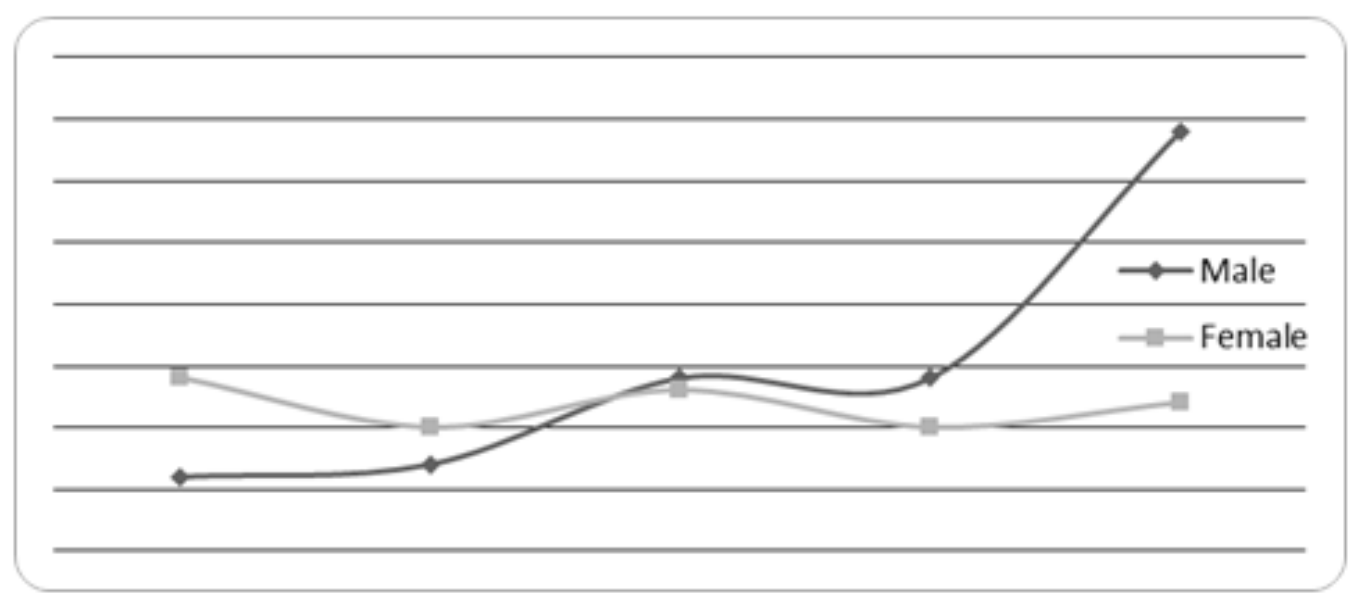

Figure3. Average Age Distribution of Both the Male and Female Respondents

However, Figure 2 showed the relationship among the age distribution between the male and female respondents. The linear graph in Figure 3 showed that the average ages of both the male and female respondents fell within the age range of 31 - 35 years recording 20.2\%. In other words, this result indicated that the average male and females respondents for this study were youths.

Table4. Respondents' Marital Status

\begin{tabular}{|l|l|l|}
\hline & Frequency & $(\mathbf{\%})$ \\
\hline Single & 37 & 27.6 \\
\hline Married & 93 & 69.4 \\
\hline Divorced & - & - \\
\hline Separated & 2 & 1.5 \\
\hline Widow/Widower & 2 & 15 \\
\hline & $\mathbf{1 3 4}$ & $\mathbf{1 0 0}$ \\
\hline
\end{tabular}

Source. Field Survey, 2020 


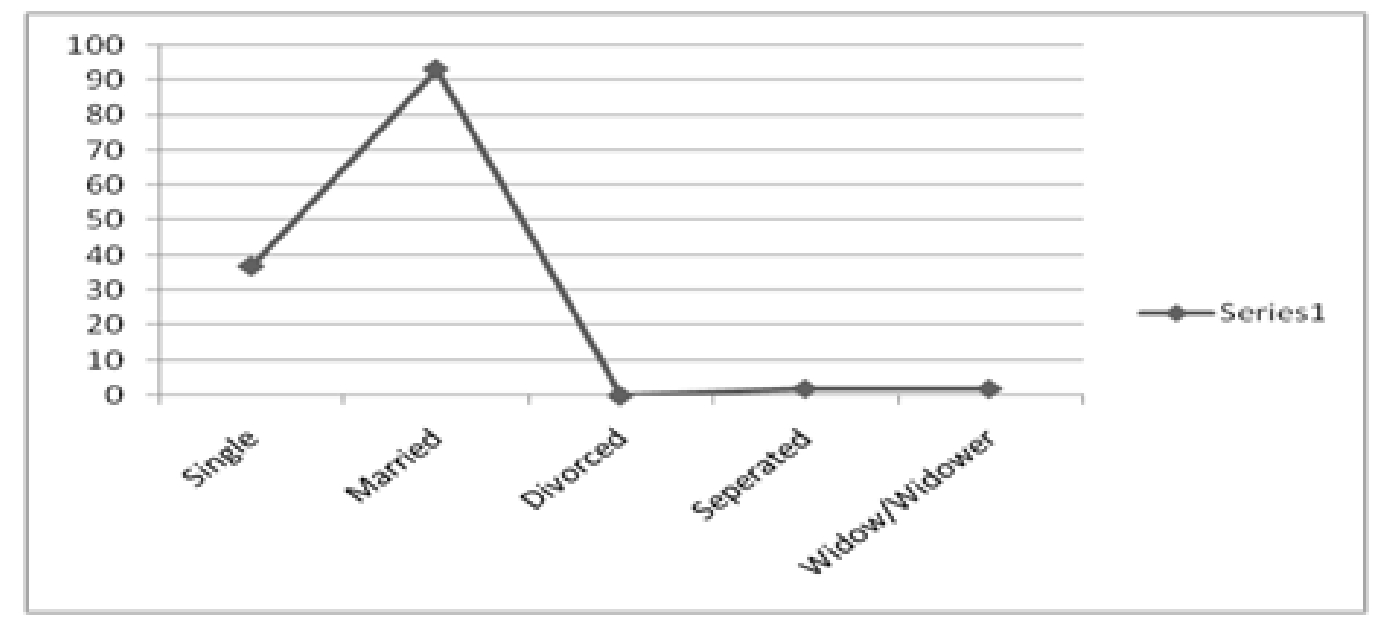

Figure4. Respondents' Marital Status

On the marital status majority, 93 out of 134 respondents $(69.4 \%)$ were married, followed by the singles, 37 respondents $(27.6 \%)$ and both the separated and the widow/widower recording two respondents $(1.5 \%)$ respectively. From the result above, we can deduce that the newspaper reading culture is more grounded with the married.

Table5. Respondents' Occupation

\begin{tabular}{|l|l|l|}
\hline & Frequency & $(\mathbf{\%})$ \\
\hline Students & 19 & 15.2 \\
\hline Civil servants & 57 & 42.5 \\
\hline Artisan s & 8 & 5 \\
\hline Retirees & 2 & 1.5 \\
\hline Unemployed & 7 & 5.2 \\
\hline Professionals & 41 & 30.6 \\
\hline & $\mathbf{1 3 4}$ & $\mathbf{1 0 0}$ \\
\hline
\end{tabular}

Source: Field Survey, 2020

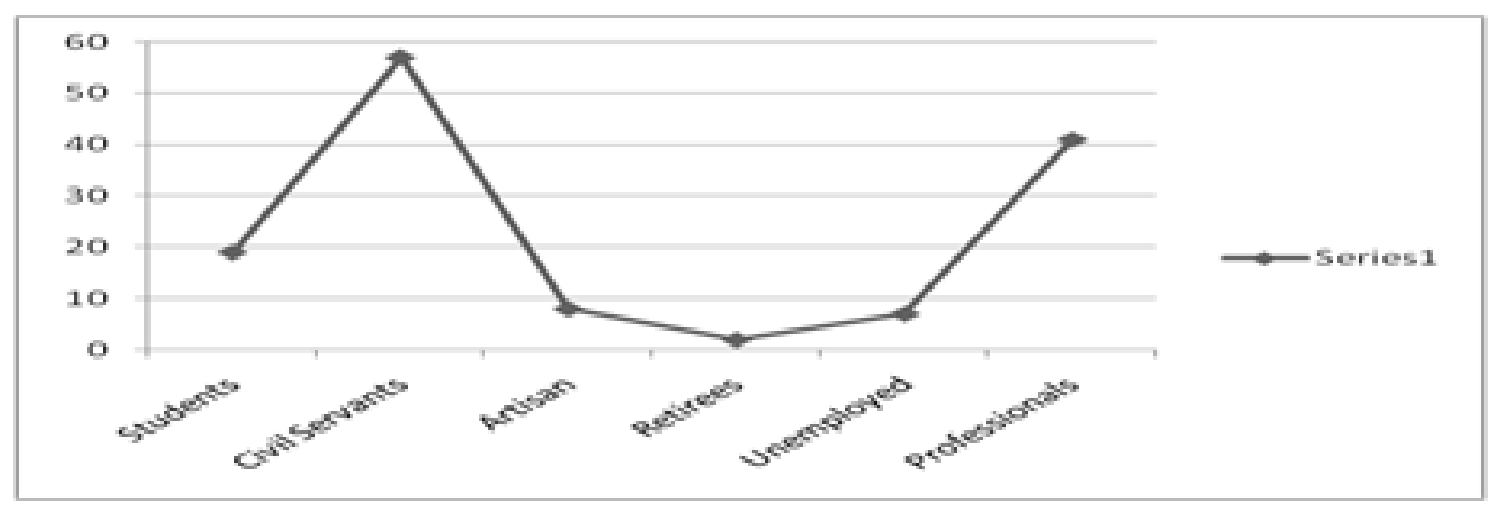

Figure5. Respondents' Occupation

The civil servants were more among the respondents $(42.5 \%) .41(30.6 \%)$ were professionals in the private sector, $19(15.2 \%)$ were students, $7(5.2 \%)$ were unemployed, $6(5 \%)$ were artisans and 2 $(1.5 \%)$ were retirees.

Table6. Respondents' Educational Qualification

\begin{tabular}{|l|l|l|}
\hline & Frequency & $(\boldsymbol{\%})$ \\
\hline WASC/SSCE/NECO & 13 & 9.7 \\
\hline OND/NCE & 26 & 19.4 \\
\hline HND/BA/B. Sc. & 72 & 53.7 \\
\hline M.Sc. /M.A./MPhil. & 19 & 14.2 \\
\hline PhD & 4 & 3 \\
\hline & $\mathbf{1 3 4}$ & $\mathbf{1 0 0}$ \\
\hline
\end{tabular}

Source: Field Survey, 2020

International Journal of Media, Journalism and Mass Communications (IJMJMC) 


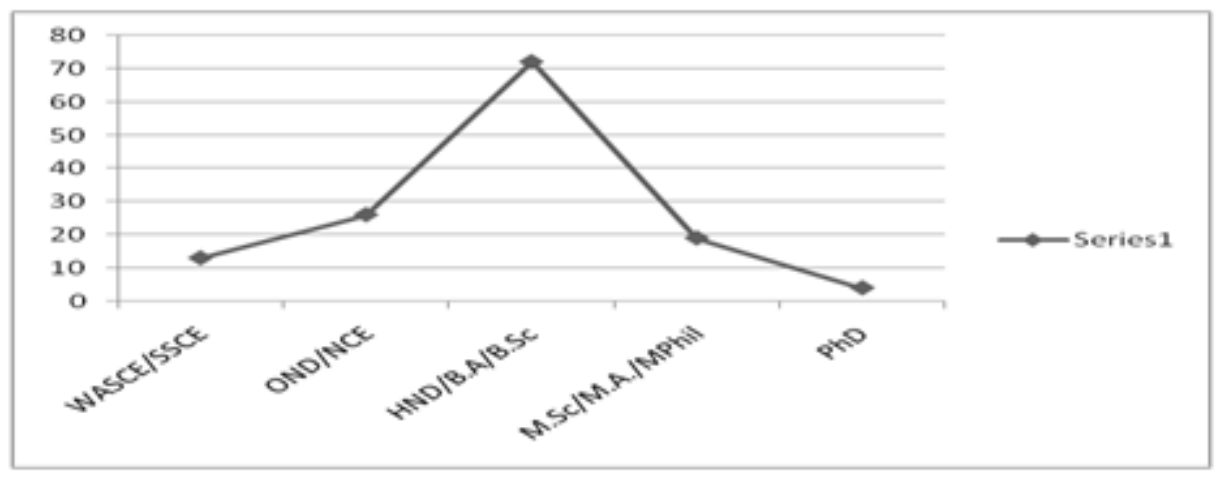

Figure6. Respondents' Educational Qualification

68 (56.2\%) first degree, 21 (17.4\%) OND/NCE, 18 respondents (14.8\%) have their higher degree (M.Sc. / M.A. / MPhil.) while 10 respondents secured O'level qualification WASC/ SSCE/NECO and four (4) respondents $(3.3 \%)$ have $\mathrm{PhD}$. From the result above, we can deduce that the respondents sampled are literates and qualified enough to understand the questionnaire.

\section{Research Question1: How efficient is the proficiency of editorial cartoon as a communication medium by The Punch and The Guardian?}

Questions 8, 9, 10,11, 18, 19 and 20 of the questionnaire were analyzed for this research question.

Table7. Efficiency on the use of Editorial Cartoons

\begin{tabular}{llllr}
\hline No. Questions & Responses & Frequency & $\%$ \\
\hline \multirow{3}{*}{$8 \quad$ Do you read the cartoons } & (A) Regularly & 30 & \\
& section? & (B) Sometimes & 60 & 22.3 \\
& (C) Often & 12 & 44.8 \\
& (D) Seldom & 20 & 14.9 \\
& (E) Never & 12 & 9
\end{tabular}

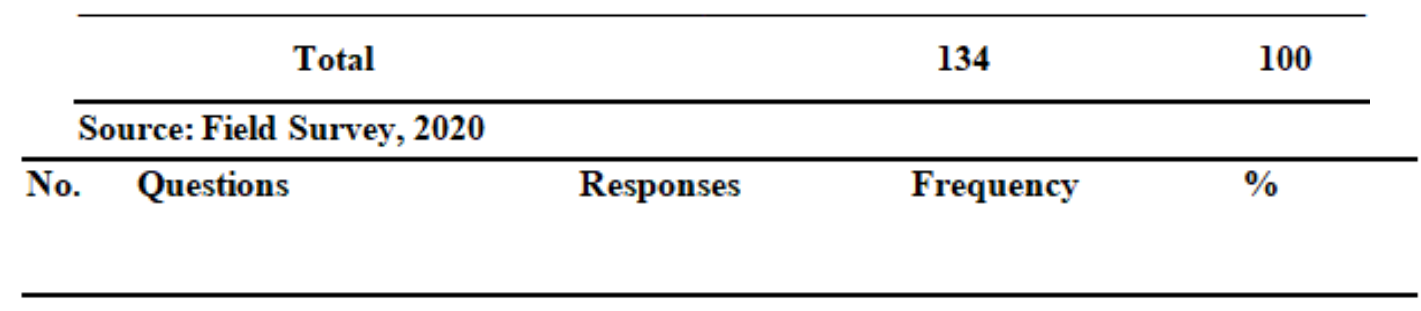

$9 \quad$ How frequently? (A) Everyday $\quad 28$

(B) At least once in a week $\quad 58 \quad 43.3$

(C) At least once in two weeks $17 \quad 12.7$

(D) At least once in a month $\quad 21 \quad 15.7$

(E) Never $\quad 10 \quad 7.5$

Total $134 \quad 100$




\begin{tabular}{llll}
\hline No. Questions & Responses & Frequency & $\%$ \\
\hline
\end{tabular}

$\begin{array}{llcr}10 \text { Why do you read } & \text { (A) For Entertainment } & 66 & 49.3 \\ \text { cartoons? } & \text { (B) For Information } & 34 & 25.4 \\ & \text { (C) For Political Awareness } & 7 & 5.2 \\ \text { (D) For Education } & 9 & 6.7 \\ \text { (E) All of the above } & 11 & 8.2 \\ & \text { (F) None of the above } & 7 & 5.2\end{array}$

Total

134

100

Source: Field Survey, 2020

No. Questions

Responses

Frequency

$\%$

\begin{tabular}{lllc}
\hline & & & \\
Do you prefer cartoons to & (A) Regularly & 11 & 8.2 \\
new stories in the delivery of & (B) Sometimes & 66 & 49.2 \\
message or information? & (C) Often & 8 & 6 \\
& (D) Seldom & 17 & 12.7 \\
& (E) Never & 32 & 23.9 \\
\hline \multicolumn{1}{c}{ Total } & & & \\
\hline Source: Field Survey, 2020 & $\mathbf{1 3 4}$ & \\
\hline
\end{tabular}

Source: Field Survey, 2020

Responses

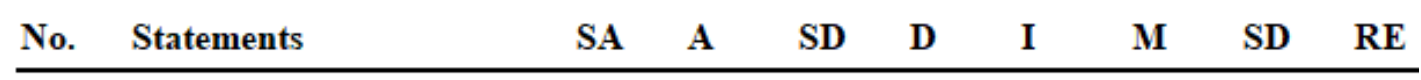

18 Cartoons' usage as a

medium of communication

$\begin{array}{lllllllllll}\text { is effective } & 39 & 77 & 6 & 8 & 4 & 4.04 & 0.92 & \text { A }\end{array}$

$\begin{array}{llllllllll}19 & \text { I don't like to read cartoons } & 9 & 8 & 52 & 60 & 5 & 2.67 & 0.91 & \text { A }\end{array}$

20 Cartoons' comic nature

influences the reading of

$\begin{array}{lllllllll}\text { newspaper } & 21 & 77 & 9 & 12 & 15 & 3.57 & 1.19 & \text { A }\end{array}$

Source: Field Survey, 2020 
The result revealed very high efficiency in the use of editorial cartoon as reported by majority of the respondents $(\mathbf{M}=\mathbf{3 . 4})$.

Research Question 2:

To what extent do the readers perceive the message of the newspaper editorial cartoons by The Punch and The Guardian?

Questions 14, 17, 21 and 22 of the questionnaire were analyzed to answer the research question

Table8. Readers' Perception of Editorial Cartoons

\begin{tabular}{|c|c|c|c|c|c|c|c|c|c|}
\hline \multirow[b]{2}{*}{$\begin{array}{l}\text { No. } \\
\text { RE }\end{array}$} & \multirow[b]{2}{*}{ Statements } & \multirow[b]{2}{*}{ SA } & \multirow[b]{2}{*}{$\mathbf{A}$} & \multirow[b]{2}{*}{ SD } & \multicolumn{3}{|c|}{ Responses } & \multirow[b]{2}{*}{ SD } & \\
\hline & & & & & $\mathbf{D}$ & I & $\mathbf{M}$ & & \\
\hline \multirow[t]{2}{*}{14} & $\begin{array}{l}\text { I understand the message } \\
\text { cartoons pass across }\end{array}$ & & & & & & & & \\
\hline & when 1 read & 46 & 77 & 1 & 6 & 4 & 4.16 & 0.88 & A \\
\hline \multirow[t]{2}{*}{17} & I feel entertained when & & & & & & & & \\
\hline & read cartoons & 46 & 73 & 4 & 7 & 4 & 4.12 & 0.92 & A \\
\hline \multirow[t]{2}{*}{21} & $\begin{array}{l}\text { I like to read more of } \\
\text { cartoons because I }\end{array}$ & & & & & & & & \\
\hline & find it funny & 51 & 61 & 5 & 9 & 8 & 4.03 & 1.11 & A \\
\hline \multirow[t]{2}{*}{22} & $\begin{array}{l}\text { I like to read more of } \\
\text { cartoons because I }\end{array}$ & & & & & & & & \\
\hline & find it informative & 33 & 70 & 11 & 12 & 8 & 3.81 & 1.09 & A \\
\hline
\end{tabular}

Source: Field Survey, 2020

The result revealed very high perception efficiency on the use of editorial cartoon in the use of editorial cartoon as reported by majority of the respondents $(\mathbf{M}=\mathbf{4 . 0 3})$.

\subsection{Discussion of Findings}

To determine the proficiency of editorial cartoon as a communication medium by The Punch and The Guardian newspapers, Table 7 revealed that $67.1 \%$ of the selected respondents believed that editorial cartoons are now fundamental section of the newspapers as $22.3 \%$ of the respondents said they read the editorial cartoons' section of the newspapers 'regularly' while $44.8 \%$ said they read the editorial cartoons' section 'sometimes' and $43.3 \%$ of the respondents read cartoons' sections 'weekly' besides the $20.8 \%$ respondents that read 'everyday'. On the other hand, the results from the table showed that $49.3 \%$ of the respondents read editorial cartoons for 'Entertainment' while $25.4 \%$ read for 'Information'.

This is contrary to the submission that some people are of the view that cartoons do not play any significant role in the society because it is a phenomenon of educated people and of those people who have awareness and knowledge of the situations and issues that are portrayed in the cartoons (Ashfaq and Hussein, 2013). Not even in an instance where $49.2 \%$ of the respondents sometimes prefer cartoons to new stories in the delivery of message or information.

However, the importance of editorial cartoon communication cannot be denied as 77 out of the 134 respondents agreed that 'cartoons' usage as a medium of communication is effective'. With 112 out of 
the 134 respondents $(83.6 \%)$ indicating their interests in reading cartoons and 77 out of the 134 respondents (57.4\%) saying 'cartoons' comic nature influences the reading of newspaper'.

To address the research question that focuses on to what extent newspaper readers perceive message of the illustrative materials like newspaper editorial cartoons by The Punch and The Guardian, the Table 8 observed that 77 out of the 134 respondents (57.5\%) agreed that they understand the message cartoons pass across when they read. With 73 out of the 134 respondents (54.5\%) feeling entertained when they read cartoons, 61 out of the 134 respondents (45.5\%) said they like to read more of cartoons because they find it funny while 70 out of the 134 respondents $(52.2 \%)$ like to read more of cartoons because they find it informative.

\section{CONCLUSION}

This paper has demonstrated how cartoons are used to accomplish communicative tasks in Nigerian print media and how the cartoons are creatively used to set agenda thereby providing political commentary and debate in witty and artful fashion through which social realities are mirrored in the nation's wider socio-political arena (Sani, et al, 2012). Therefore, the paper has shown that the cartoon genre constitutes a formidable medium of communication through which the media set social agenda by attaching relevance to importance of issues and events through recurrent coverage aimed at shaping the people's understanding of the issues to bring positive change in society. Thus, Nigerian political cartoons serve as agent of setting social agenda used by the media specifically to build up public attention, reorient people and initiate social and political reforms in Nigeria (Adetola and Abioye, 2020).

It is evident that cartoons published in newspapers are critical of the present situation's problems, personalities and institutions, as it can be said that cartoons are the chronicle of current history. This paper sees cartooning as a strategy that reflects the intention of cartoonists to communicate problems that affect society in a subtle way in order to find a panacea for political and social ills. It is observed that cartoonists usually pick up the subject of the cartoons through the editorials which is presented in the newspapers and vice versa (Kinyua, 2014). Hence, there is no doubt that there is more to give than entertaining readers in editorial cartoons. Editorial cartoons are therefore intended to instigate a reflection on what is happening in a society (Adetola and Abioye, 2020).

\section{RECOMMENDATIONS}

Though the use of cartoons in newspaper publications was efficient, as really was there any published edition without editorial cartoons as it was very unusual, but not many print organizations leverage their use for information dissemination as most published editorial cartoons focused more on politics than other social issues. In addition to politics, cartoonists should also examine social problems because it is a light medium and it is easier to highlight people's voices as compared to columns or other newspaper articles. Meanwhile, the newspapers' readers understood what editorial cartoons are to a great extent and they read editorial cartoons for different purposes, the most reoccurring of which is for entertainment, besides information, education and political awareness, however, print media should also concentrate on how graphic images can be read and understood for messages dissemination.

\section{BIBLIOGRAPHY}

[1] Adetola, S. A. (2019). Uses and Gratification of Editorial Cartoons as Medium of Communication by Two National Newspapers. (Master's thesis). Lead City University, Ibadan, Nigeria.

[2] Adetola, S. A. and Abioye, L. A. (2020). Uses and Gratification of Editorial Cartoons as Medium of Communication by Two Nigeria National Newspapers. International Journal of Media, Journalism and Mass Communications (IJMJMC), 6 (2), 30-42 doi: http://dx.doi.org/10.20431/2454-9479.0602004.

[3] Agba J. U. (2014). The Search for New Roles for Cartoon Art: Promoting Democracy in Nigeria through Innuendos of Political Communication. J Mass Communicat Journalism, 4 (2): 2 - 3.

[4] Agundu A. P. (2017). Impact of Educational Cartoons on the Learning Ability of Children in Nigeria. (B.Sc. Thesis). Lead City University, Ibadan.

[5] Asemah, E. S. (2011). Selected mass media themes. Jos: University Press.

[6] Ashfaq A. and Hussein A. (2013). Political Cartoonists versus Readers: Role of political cartoonists in Building Public Opinion and Readers' Expectations towards Print Media Cartoons in Pakistan. Mediterranean Journal of Social Sciences 4 (3): 268 - 271. 
[7] Baran S. J. and Davis D. K. (2010). Mass Communication Theory: Foundations, Ferment, and Future, Sixth Edition. Wadsworth, Cengage Learning.

[8] Burrell, G. and G. Morgan. (1979). Sociological Paradigms and Organisation Analysis. London: Heinemann.

[9] Fahmy, S., Bock, M. A., \& Wanta, W. (2014). Visual Communication Theory and Research, A Mass Communication Perspective. New York: Palgrave Macmillan.

[10] Gravetter F. and Forzano L. (2009). Research Methods for the Behavioral Sciences. USA: Wadsworth, Cengage Learning, Third Edition.

[11] Guy, B. B. (2016). Newspaper Editorial Cartoons: Where Art, Rhetoric and Metaphor meet Reality. (Doctor in Philosophy Thesis). University of Liverpool.

[12] Mapuwei N. (2014). A social-semiotic engagement with representations of President Robert Mugabe and Prime Minister Morgan Tsvangirai in The ZimDaily.com from June 2008 to July 2013. African Journal of Political Science and International Relations, 8. (7): 238 - 239.

[13] Matthews C. A. (2011). Wittiism of Transition: Humor and Rhetoric of Editorial Cartoons on Journalism. (Master of Arts Thesis). University of Missouri-Columbia.

[14] Miller, K. (2005). Communication Theories: Perspectives, Processes, and Contexts. New York: McGrawHill.

[15] Moerman, M. (1992). “Life After C. A.: An Ethnographer's Autobiography.” In G. Watson and

[16] R. M. Seller, eds., Text in Context: Contributions to Ethnomethodology. Newbury Park, CA: Sage.

[17] Mwetulundila, R. \& Kangira, J. (2015). An Analysis of Rhetoric and Humour in Dudley's Political Cartoons Published in the Namibian Newspaper in 2012. International Journal of Research in Humanities and Social Studies, 2 (6), 65.

[18] Naghy, E. C. (2010). Directing Ideologies through Media Cartoons. (MA Dissertation). Universidad Complutense De Madrid.

[19] Okoro N. and Onakpa M. (2016). Audience Perception of Television Animated Cartoons as Tool for Political Communication: A Study of Selected Towns in North Central Nigeria. International Journal of Arts and Humanities (IJAH), 5. (4), 232-249.

[20] Ihebuzor L. (2017). Principles and Practice of Book Publishing in Nigeria. Lagos and Owerri: Sibon Books Limited.

[21] Jimoh, G. A. (2010). The Role of Editorial Cartoons in the Democratisation Process in Nigeria: A Study of Selected Works of Three Nigerian Cartoonists. (A dissertation). University of Lagos.

[22] Kinyua, W. J. (2014). Decoding Cartoons: The Explicatures and Implicatures of Editorial Cartoons in The Daily Ntaion. (A research of Master of Arts in Linguistics). The University of Nairobi.

[23] Pitcher S. (2016). Deviant Doodling: Contextualising the Discourses of Zapiro in a Socially Responsible Press. (A doctor of Philosophy Degree). University of KwaZulu - Natal Pietermaritzbur.

[24] Sani, I., Abdullah, M. H., Abdullah, F. S. \& Ali, A. M. (2012). Political Cartoons as a Vehicle of Setting Social Agenda: The Newspaper Example. Journal of Asian Social Science, 8 (6), 150-164.

[25] Schutt, R. K. (2009). Investigating the Social World, 6th ed. Thousand Oaks, CA: Sage.

\section{APPENDIX}

\section{Audience perception of editorial cartoons questionnaire (APECQ) section a: demographic information}

Please, kindly tick $(\sqrt{ })$ in any of the boxes provided where applicable.
1) Sex: Male
Female ( )
2) Age:
$21-25()$
above ( )
$26-30()$
$31-35()$
$36-40$ ( ) 41and

3) Marital Status:

Single ( )

Married ( )

Divorced ( )

Separated ( )

Widow/Widower ( )

4) Occupation:

Student ( ) Civil Servant ( ) Artisan ( ) Retiree ( )

Professional in Private Sector ( ) Unemployed ( )

5) Educational Qualification:

SSCE/GCE ( ) OND/NCE ( ) HND/BSc/B.A ( ) MSc/MPhil ( )
$\mathrm{PhD} \mathrm{(} \mathrm{)}$

\section{Section B: $\quad$ Questions on Communicative Roles of Editorial Cartoons}


6) Do you read newspapers? Regularly ( ) Sometimes ( ) Often ( )

$$
\text { Seldom () Never () }
$$

7) Which of these national newspapers do you read?

( ) The Guardian () Both () Others ()

None ( )

8) Do you read the cartoon section? Regularly ( ) Sometimes ()

Seldom ( ) Never ( )

9) How frequently? Every day ( ) At least once in a week ( )

At least once in two weeks ( ) At least once in a month ( )

The Punch

0) Why do you read cartoons? For Entertainment ( )

For Information ( )

Never ( )

Political Awareness ( )

For Education ( )

All of the above ( )

None of the above ()

11) Do you prefer cartoons to new stories in the delivery of message or information?

Regularly
) Sometimes ( )
Often ( )
Seldom ( )
Never ( )

\section{Section C: Questions on Audience Perception on Editorial Cartoons}

Kindly tick $(\sqrt{ })$ appropriately on your degree of agreement with any of the following statements below as $\mathbf{S A}=$ Strongly Agree, $\mathbf{A}=$ Agree, $\mathbf{S D}=$ Strongly Disagree, $\mathbf{D}=$ Disagree, $\mathbf{I}=$ Indifference .

\begin{tabular}{|c|c|c|c|c|c|c|}
\hline $\mathbf{S} / \mathbf{N}$ & Comprehension achieved by readers of editorial cartoons & $\mathbf{S A}$ & $\mathbf{A}$ & SD & D & I \\
\hline 12 & Cartoons keep me abreast of the socio-political on-going & & & & & \\
\hline 13 & Cartoons pass across useful information to the public & & & & & \\
\hline 14 & I understand the message cartoons pass across when 1 read & & & & & \\
\hline \multirow[t]{2}{*}{15} & Cartoons keep me more interested in reading the newspaper & & & & & \\
\hline & $\begin{array}{l}\text { What is the readers' perception on editorial cartoons as a medium of } \\
\text { communication? }\end{array}$ & $\mathbf{S A}$ & $\mathbf{A}$ & SD & $\mathbf{D}$ & $\mathbf{I}$ \\
\hline 16 & Cartoon influences me positively through its message & & & & & \\
\hline 17 & I feel entertained when 1 read cartoons & & & & & \\
\hline 18 & Cartoons' usage as a medium of communication is effective & & & & & \\
\hline \multirow[t]{2}{*}{19} & I don't like to read cartoons & & & & & \\
\hline & What are the factors influencing reading of newspapers' cartoons? & $\mathbf{S A}$ & $\mathbf{A}$ & SD & $\mathbf{D}$ & $\mathbf{I}$ \\
\hline 20 & Cartoons' comic nature influences the reading of newspaper & & & & & \\
\hline 21 & I like to read more of cartoons because I find it funny & & & & & \\
\hline 22 & I like to read more of cartoons because I find it informative & & & & & \\
\hline \multirow[t]{2}{*}{23} & Pictures in cartoons interest me more than the cartoons' messages & & & & & \\
\hline & $\begin{array}{l}\text { How can newspapers' cartoonists improve on cartoons so as to be } \\
\text { medium of communication? }\end{array}$ & SA & $\mathbf{A}$ & SD & $\mathbf{D}$ & I \\
\hline 24 & Cartoons' illustrations should be made more informative and educative & & & & & \\
\hline 25 & $\begin{array}{l}\text { Cartoonists should ensure that the cartoons texts correlate with the } \\
\text { images depicted }\end{array}$ & & & & & \\
\hline 26 & $\begin{array}{l}\text { Cartoonists should make their cartoons' sketches (visual illustrations) } \\
\text { more attractive to readers }\end{array}$ & & & & & \\
\hline 27 & $\begin{array}{l}\text { Cartoonists should ensure dissemination of educative information to } \\
\text { readers through their comic sins and visual illustrations }\end{array}$ & & & & & \\
\hline
\end{tabular}

Citation: ADETOLA, Samson Adesegun, OLUYI, Isaac Adesuyi. 'Audience Perception of Newspapers' Editorial Cartoons as Communication Medium". International Journal of Media, Journalism and Mass Communications (IJMJMC), vol 6, no. 3, 2020, pp. 40-54 doi: http://dx.doi.org/10.20431/2454-9479.0603004.

Copyright: () 2020 Authors. This is an open-access article distributed under the terms of the Creative Commons Attribution License, which permits unrestricted use, distribution, and reproduction in any medium, provided the original author and source are credited. 